\title{
Correction to: lleocecal valve syndrome and vitamin b12 deficiency after surgery: a multicentric prospective study
}

\author{
Paola Germani ${ }^{1}$ [ - Annalisa Zucca ${ }^{1}$. Fabiola Giudici ${ }^{1}$ - Susanna Terranova ${ }^{1}$ Marina Troian ${ }^{1}$. \\ Natasa Samardzic ${ }^{1} \cdot$ Marco Greco $^{2}$ - Jurij Janez ${ }^{3}$. Camilla Gasparini ${ }^{4} \cdot$ Emanuela Cagnazzo $^{5} \cdot$ Andrea Vignali $^{6}$. \\ Fabio Giannone Codiglione ${ }^{6} \cdot$ Andrea Armellini $^{7} \cdot$ Uberto Romario Fumagalli $^{7} \cdot$ Riccardo Rosati $^{6}$. \\ Giuseppe Piccinni $^{5}$. Jacques Megevand ${ }^{4}$ - Ales Tomazic $^{3}$. Francesco Corcione ${ }^{2}$. Silvia Palmisano ${ }^{1}$. \\ Nicolò de Manzini ${ }^{1}$
}

Published online: 1 August 2020

(c) The Author(s) 2020

\section{Correction to: Updates in Surgery https://doi.org/10.1007/s13304-020-00845-z}

One of the co-author Eliana Cagnazzo has been incorrectly published. The correct co-author name has been copied below:

Emanuela Cagnazzo

The original article has been corrected.

Open Access This article is licensed under a Creative Commons Attribution 4.0 International License, which permits use, sharing, adaptation, distribution and reproduction in any medium or format, as long as you give appropriate credit to the original author(s) and the source, provide a link to the Creative Commons licence, and indicate if changes were made. The images or other third party material in this article are included in the article's Creative Commons licence, unless indicated otherwise in a credit line to the material. If material is not included in the article's Creative Commons licence and your intended use is not permitted by statutory regulation or exceeds the permitted use, you will need to obtain permission directly from the copyright holder. To view a copy of this licence, visit http://creativecommons.org/licenses/by/4.0/.

Publisher's Note Springer Nature remains neutral with regard to jurisdictional claims in published maps and institutional affiliations.
The original article can be found online at https://doi.org/10.1007/ s13304-020-00845-z.

\section{Paola Germani}

paolagermani1987@gmail.com

1 General Surgery Clinic, Department of Medical, Surgical and Health Sciences, University of Trieste, University Hospital of Trieste, Trieste, Italy

2 General Surgery, Azienda Ospedaliera Dei Colli, Monaldi Hospital, Naples, Italy

3 Department of Abdominal Surgery, Ljubljana University Medical Center, Ljubljana, Slovenia

4 General Surgery, San Pio X Humanitas Research Hospital, Milan, Italy

5 General Surgery, Santa Maria Hospital GVM Care and Research, Bari, Italy

6 Department of Gastrointestinal Surgery, San Raffaele Hospital, Vita-Salute San Raffaele University, Milan, Italy

7 General Surgery 2, Ospedali Civili, Brescia, Italy 